\title{
How can we teach astrobiology and survive?
}

\author{
Telma Rodrigues ${ }^{\mathrm{a}}$ and Francisco Carrapiço ${ }^{\mathrm{b}}$ \\ Universidade de Lisboa, Faculdade de Ciências, Departamento de Biologia Vegetal, Centro de \\ Biologia Ambiental, Bloco C2, Campo Grande, 1749-016 Lisboa, Portugal
}

\begin{abstract}
Making science was and always will be a continuous challenge; however teaching science is a step forth. A good example is astrobiology. Defined as the scientific study of biological processes on Earth and beyond, it connects research in chemistry, physics, biology, geology, astronomy and planetary sciences. This interconnected scientific network allows us to visualize a new approach of the life's nature and its origins and development on Earth and elsewhere in the universe. With these goals, we wish to look within the nature of life, observing a new paradigm in the construction of the scientific knowledge.

Teaching astrobiology is not an easy task. There are several constrains, such as treating and integrating diverse areas of knowledge and teaching a science that embraces so many questions presently unanswered and on which students have so many doubts and wrong pre-instructional beliefs. Another obstacle is the rapidly spreading of Intelligent Design, the new incarnation of creationism, which considers astrobiology as a danger for its policies, dogmas and philosophy. However, the principal barrier for teaching astrobiology is, without doubt, the difficulty to integrate this science in the curricular domain.
\end{abstract}

Keywords: teaching astrobiology, public outreach, challenge, new paradigm.

\section{INTRODUCTION}

During human history there have been several thinkers, philosophers and scientists seeking the origins and the meaning of life. This led to diverse perspectives and explanations, the majority being related to divine connotations. Meanwhile, astrobiology provided a scientific discussion in this matter presenting an alternative to the existence of an intelligent creator.

Astrobiology studies life in the universe, its origins, evolution and distribution. With this propose this science also pursues the nature of life and what it needs to occur and develop. This knowledge has changed with time. Before the 70 's, until the discovery of hydrothermal vents ${ }^{1}$ and the communities of organisms which live there at high depths, no one ever though that life could be possible without sunlight. Other similar discoveries of organisms living in extreme conditions, such as high temperatures, in highly acidic environments or in adverse radiation conditions also played an important role in the construction of scientific knowledge of astrobiology ${ }^{2}$. These discoveries are being made concomitantly with discoveries that strongly suggest that running water was present on the surface of Mars in the past ${ }^{3,4}$, the likely existence of liquid water oceans beneath the icy surface of Jupiter's moon Europa ${ }^{5}$, and the presence of a liquid ocean of hydrocarbons in Saturn's moon Titan ${ }^{6}$.

This rapidly evolving area of knowledge, with a truly multi and trans-disciplinary nature, should be public widespread and ultimately integrated into the curricular domain, as well as into public and private scientific policies ${ }^{7}$. Although some resistance and several handicaps emerge, an effort should be made by teachers and astrobiology researchers to implement astrobiology in education.

atelmarodrigues@oniduo.pt; ${ }^{\mathrm{b}}$ f.carrapico@fc.ul.pt

Instruments, Methods, and Missions for Astrobiology IX, edited by

Richard B. Hoover, Gilbert V. Levin, Alexei Yu. Rozanov, Alexander Spirin,

Proc. of SPIE Vol. 6309, 63090R, (2006) · 0277-786X/06/\$15 - doi: 10.1117/12.681950

Proc. of SPIE Vol. 6309 63090R-1 


\section{TEACHING ASTROBIOLOGY AS A NEW PARADIGM IN EDUCATION}

Astrobiology is a new multi and trans-disciplinary field of knowledge which allows the real integration of several areas of knowledge, traditionally kept apart. In this sense, new broader curricula can be designed making possible the development of more holistic learning and contributing to the flexibility of the students' mental structure ${ }^{8}$.

Moreover, this new science is an excellent example for teaching the dynamic construction of scientific knowledge, once it deals with ancient questions like the origins of life, and in another way, reveals some of the most exciting and recent discoveries. The subject of this science is also excellent to fight back the scientific illiteracy in the society and to promote some important changes in mentalities. The approach to open questions such as the origin of life and its distribution in the universe is exceptional to discuss science, to test the scientific method and to develop the critical spirit ${ }^{9}$.

Finally, astrobiology also plays an important ecological role in our perception of the world. Seeking life beyond Earth removed our established boundaries, "our world" is no longer Earth it became the whole Universe. This new approach can jeopardize not only the long-term built science, but also other areas of our knowledge and in some cases the well established certainties of the society.

For all the above we consider teaching astrobiology a new revolutionary paradigm in education, in which all efforts should be combined in order to promote its development and subsequent integration in the curricular domain. As we haven't achieved this goal yet, an alternative to implement education and public outreach is the realization of extracurricular projects in schools and public workshops. In this sense, we have developed in Portugal several activities.

During the period 2000-2003 we developed the project "A Journey to the Origins - Astrobiology in the Lab" (20002003) in co-operation with the Centre for Environmental Biology/Department of Plant Biology and the Centre for Educational Research/Department of Education of the Faculty of Sciences, University of Lisbon and the Emídio Navarro's High School. The project was sponsored by the Program Ciência Viva - Ministry of Science and Technology (MCT) and jointed by a multidisciplinary team involving teachers and researchers on Biology, Geology, Informatics, Science Education and a class of 10th grade students of Biology and Geology. In the framework of this project, the students developed lab activities (such as Redi, Spallanzani and Oparin experiments; lab activities on experimentation with halophiles microorganisms under diverse environmental conditions), field trips (for example, visits to saltpans to study environmental conditions and collect biological material) and the use of Internet as a searching tool for the astrobiology knowledge (Figures 1, 2 and 3). These activities were presented to the community in an Open Laboratory Day, Emídio Navarro's homepage, conferences and the presentation of a digital portfolio with all the materials developed by the teachers and students during the project.

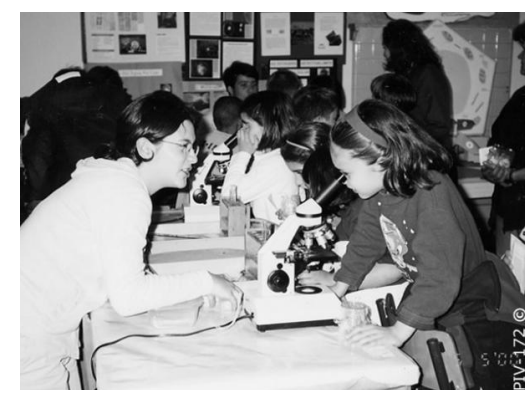

Fig. 1. Lab activities at the Open Laboratory Day, Emídio Navarro's High School.

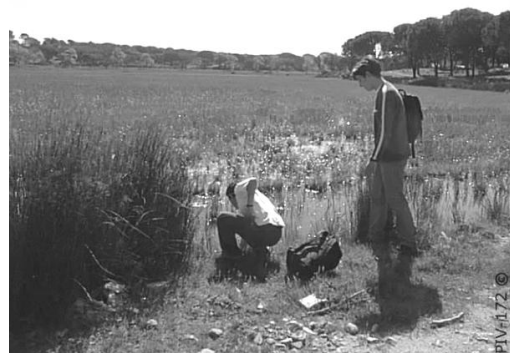

Fig. 2. Field Trip to saltpans to study environmental conditions and collect biological material.

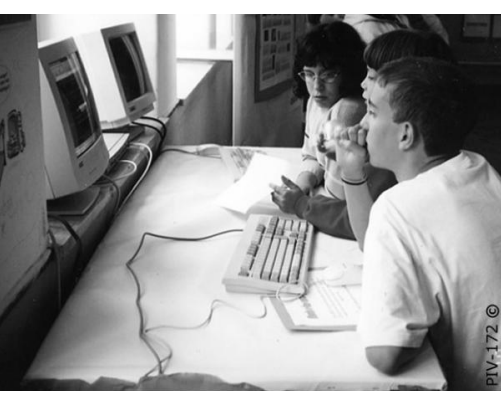

Fig. 3. Internet Research. at the Open Laboratory Day, Emídio Navarro's High School.

In August/September of 2005 a public workshop was developed in Monserrate Park, Sintra, sponsored also by the Program Ciência Viva - Ministry of Science and Technology (MCT). This activity named "Astrobiology - A Journey to the Origin .... and to the Future of Life" started with a pedestrian trail in the referred Park, followed by a lecture and a set 
of practical activities (such as discovering where life exists in several samples; coacervate formation; macro and micro observation of lichens; and a final interactive activity) (Figures 4, 5 and 6). The evaluation done by the institution, through questionnaires to participants, was very positive.

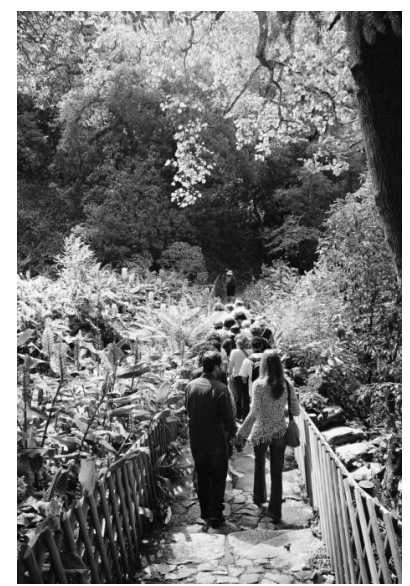

Fig. 4. Pedestrian trail in the Monserrate Park, Sintra.

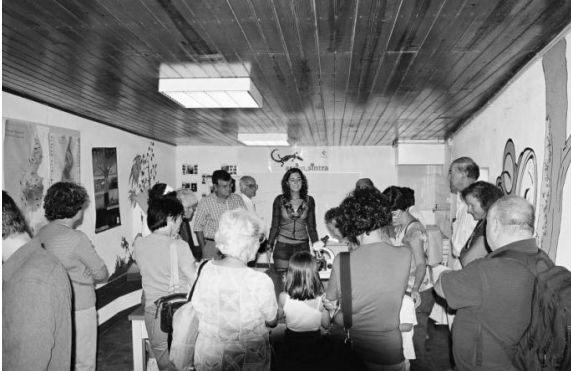

Fig. 5. Lecture in the Monserrate Park, Sintra.

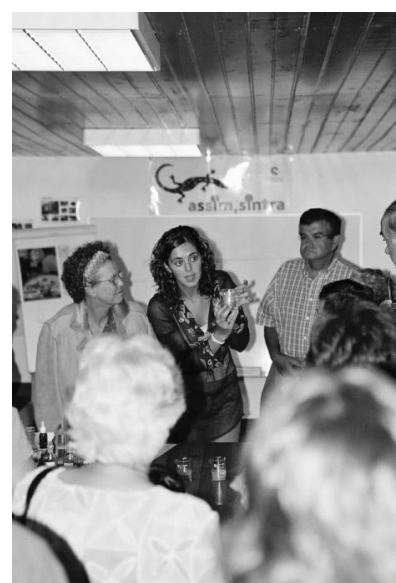

Fig. 6. Lab activities in the Monserrate Park, Sintra..

During this school year (2005/2006) an extracurricular project called "Project Astrobiology" was developed in Dr. José Afonso's High School in co-operation with the Centre for Environmental Biology/Department of Plant Biology and the Observatory Astronomical of Lisbon of the Faculty of Sciences, University of Lisbon. During this year, students also developed several lab activities (such as discovering where life exists in several samples, DNA extraction, construction of a replica from the Miller's experimental apparatus, coacervate formation, and macro and micro observation of lichens), played educational games (such as Astrobiotica ${ }^{10}$ ), attended conferences and went on field trips (for example to the Observatory Astronomical of Lisbon of the Faculty of Sciences, University of Lisbon). The students then presented their work to the community in an Open Laboratory where each group of students explored a different module concerned with life's origin, executing the lab activities referred above and explaining the implicated theories (Figures $7,8$ and 9$)$.

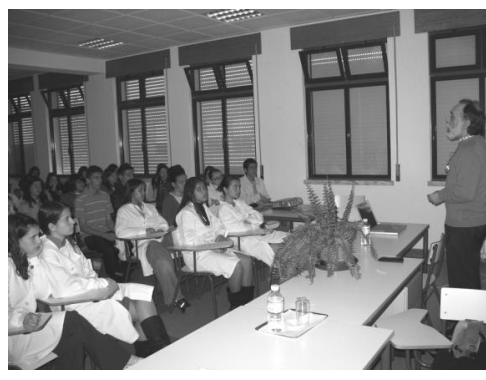

Fig. 7. Conference "Origin and Evolution of Life".

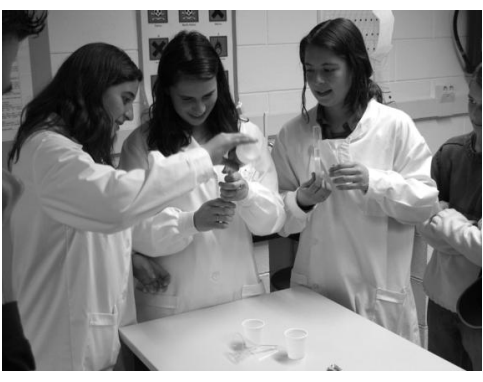

Fig. 8. Lab activities at the Open Laboratory Day.

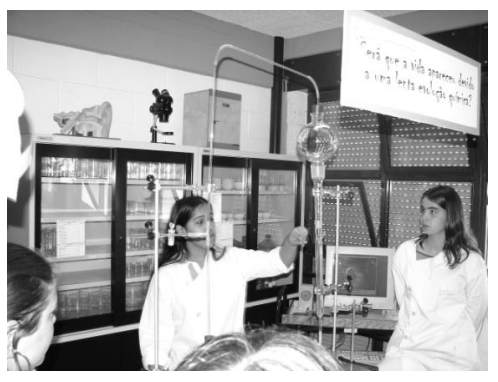

Fig. 9. Lab activities at the Open Laboratory Day.

The results obtained with all these activities were very satisfying. Students and other public participants showed enthusiasm and curiosity about astrobiology, questioning several aspects and searching for answers. They participated with dedication and motivation in all the activities developed. In the extracurricular projects it was also possible to notice an attitudinal evolution in students; they became more interested in science, their critical spirit evolved and at the end they demonstrated a different approach to the way they see the role of human species in the universe. 


\section{MAJOR CONSTRAINTS}

Teaching astrobiology is a challenge to teachers and students; to teach a discipline that integrates so many areas of knowledge (chemistry, physics, biology, geology, astronomy and planetary sciences) can sometimes be difficult but, with no doubt, is very important for comprehending science nowadays in a more significant and holistic way. Astrobiology seeks the nature of life, its origins, evolution and distribution in the universe, being therefore a field of knowledge that raises many questions, some of them difficult to provide an answer to. Despite what initially seems to be an obstacle, if the teacher knows how to explore it in an adequate way it will certain leads to a proficuous critical reflection on the nature of science, using the scientific method and developing students critical spirit.

In addition, students have numerous doubts and wrong pre-instructional beliefs in the more fundamental concepts aligned with astrobiology concerning the definition of life on Earth and its limitations ${ }^{11}$ : many students typically use "movement" and "breath" as criteria for life and incorrectly state that life cannot survive without oxygen ${ }^{11}$. In order to overtake this problem, teachers should diagnose students' pre-instructional beliefs and structure their teaching strategies in order to fulfill their needs.

Other obstacle can be the swiftly increase of the Intelligent Design movement which considers astrobiology a danger for its policies, dogmas and philosophy. "The intelligent design movement is a small but growing force on United States university campuses. For some it bridges the gap between science and faith, for others it goes beyond the pale"12. This statement by Geoff Brumfiel reveals the importance that this movement is achieving in the United States and its stronger argument: a way of reconciling people's beliefs with their interests in science ${ }^{13}$. Intelligent Design (ID) explains the existence of life as a result of an intelligent project. ID advocates explain that the specified complexity that exists in biological organisms can only be explained by being designed by an intelligent agent ${ }^{14,15}$. These authors don't mention God, they leave this question open of who that intelligent agent may be. It is obvious that this explanation goes in encounter to theological beliefs, and Christian fundamentalist groups have seized on it as a possible way to force creationism back into the classroom ${ }^{12}$. Teachers play an important role in this issue, although ID meets some of the students' beliefs, the goal of a science teacher should be to point to options other than ID for reconciling science and belief $^{13}$, and astrobiology should be the path to achieve that. The importance of this problem in the educational community, compelled the National Academy of Sciences (NAS) to publish a document entitled "Science and Creationism" "16: "The arguments of creationists are not driven by evidence that can be observed in the natural world. Special creation or supernatural intervention is not subjectable to meaningful tests, which require predicting plausible results and then checking these results through observation and experimentation. Indeed, claims of special creation reverse the scientific process. The explanation is seen unalterable, and evidence is sought only to support a particular conclusion by whatever means possible" ${ }^{16}$. And last, but not least, Bruce Alberts, President of NAS, wrote in the preface of this work a sentence that summarizes in a correct way the feelings and thoughts about the Intelligent Design - Science controversy: "Scientists, like many others, are touched with awe at the order and complexity of nature. Indeed, many scientists are deeply religious. But science and religion occupy two separate realms of human experience. Demanding that they be combined detracts from the glory of each" ${ }^{16}$.

Despite all these constrains, the principal barrier for teaching astrobiology is the difficulty to integrate this science in the curricular domain. Without this goal, the resources are limited and restricted to the availability and will of the schools/institutions to promote activities as those described above in astrobiology education and public outreach.

\section{CONCLUDING REMARKS}

In this paper we have shared our experience on astrobiology education and public outreach in Portugal during the last few years. Teaching astrobiology is not an easy task. It presents several constrains that difficult the success of astrobiology teaching and an adequate outreach. The principal barrier for teaching astrobiology is the difficulty to integrate this science in the curricular domain. However, new threats are emerging in the horizont. The main one is the development of Intelligent Design, the new incarnation of creationism, that is spreading rapidly in the educational and scientific communities and also in society in general.

We believe, however, that the firm scientific base of astrobiology, building the adequate platform for assembling knowledge and researchers of human and science fields can be a challenge to the needs of an "intelligent design" for the understanding of the origins and the meaning of life. Furthermore, it is a scientific and rational contribution to understand the role of the human species in the universe. 


\section{ACKNOWLEDGEMENTS}

Granted by the Luso-American Foundation (FLAD). The authors are grateful for the technical assistance of Helena Carrapiço.

\section{REFERENCES}

1. J. B.Corliss and R. D. Ballard, "Oases of Life in the Cold Abyss". National Geographic 152, 441-453 (1977).

2. L. J. Rothschild and R. L. Mancinelli, "Life in extreme environments". Nature 409, 1092-1101 (2001).

3. G. V. Levin, "Odyssey gives evidence for liquid water on Mars". Proceedings of SPIE 5163. (2003).

4. G. Webster and D. Savage. "Mars Rovers Spot Water-Clue Mineral, Frost, Clouds." Press Releases, http://www.nasa.gov/vision/universe/solarsystem/mer-121304b.html (2004).

5. D. A. Rothery, "Icy bodies: Europa and elsewhere." in I. Gilmour \& M. A. Sephton (Eds.), An Introduction to Astrobiology. (pp: 127-170). The Open University, Cambridge University Press, 2004.

6. C. C. Porco; E. Baker; J. Barbara; K. Beurle; A. Brahic; J. A. Burns; S. Charnoz; N. Cooper; D. D. Dawson; A. D. Del Genio; T. Denk; L. Dones; U. Dyudina; M. W. Evans; S. Fussner; B. Giese; K. Grazier; P. Helfenstein; A. P. Ingersoll; R. A. Jacobson; T. V. Johnson; A. Mcewen; C. D. Murray; G. Neukum; W. M. Owen; J. Perry; T. Roatsch; J. Spitale; S. Squyres; P. Thomas; M. Tiscareno; E. P. Turtle; A. R. Vasavada; J. Veverka; R. Wagner and R. West, "Imaging of Titan from the Cassini spacecraft". Nature 434,159-168 (2005).

7. J. T. Staley, "Astrobiology, the transcendent science: the promise of astrobiology as an integrative approach for science and engineering education and research", Current Opinion in Biotechnology. 14, 347-354 (2003).

8. T. Rodrigues and F. Carrapiço, "Teaching Astrobiology. A Scientific and a Cultural Imperative". Proceedings of SPIE 5906, 59060F-1 - 59060F-4 (2005).

9. F. Carrapiço, A. Lourenço, L. Fernandes and T. Rodrigues, "A Journey to the Origins. The Astrobiology Paradigm in Education", Proceedings of SPIE 4495, 295-300 (2002).

10. T. Rodrigues and F. Carrapiço, "Educational games: a funny way to teach Astrobiology". Proceedings of the III European Workshop on Exo-Astrobiology. Mars: The Search for Life. SP-545, 277-278 (2004).

11. E. G. Offerdahl; E. E. Prather; T. F. Slater, "Students' Pre-Instructional Beliefs and Reasoning Strategies About Astrobiology Concepts". Astronomy Education Review 1, 5-27 (2003).

12. G. Brumfiel, "Who has designs on your students' minds?". Nature 434, 1062-1065 (2005).

13. "Dealing with design". Nature 434, 1053-1065 (2005).

14. W. A. Dembski, "Detecting Design in the Natural Sciences. Intelligence leaves behind a characteristic signature" in R. Milner and V. Maestro (Eds.), "Intelligent Design? A special Report from Natural History Magazine." http://www.actionbioscience.org/evolution/nhmag.html (2002).

15. M. J. Behe, "The Challenge of Irreducible Complexity. Every living cell contains many ultrasophisticated molecular machines" " in R. Milner and V. Maestro (Eds.), "Intelligent Design? A special Report from Natural History Magazine." http://www.actionbioscience.org/evolution/nhmag.html (2002).

16. Science and Creationism. A view from the National Academy of Sciences, National Academy of Sciences, Washinghton, DC, 1999. 